\title{
Genetic Variation Analysis
}

National Cancer Institute

\section{Source}

National Cancer Institute. Genetic Variation Analysis. NCI Thesaurus. Code C18302.

The identification of genetic variation in a biological sample. 